\section{PROGNOSTIC FACTORS IN} TREATMENT OF DEPRESSIVE STATES WITH IMIPRAMINE

\author{
BY
}

L. G. KILOH, M.D., M.R.C.P., D.P.M. Reader in Psychological Medicine, University of Durham

\section{J. R. B. BALL, M.B., B.S., D.P.M.}

Senior Registrar, Department of Psychological Medicine, Royal Victoria Infirmary, Newcastle upon Tyne

$$
\text { AND }
$$

R. F. GARSIDE, B.Sc.

Senior Lecturer in Applied Psychology, University of Durham

Accurate diagnosis within the group of depressive states is generally agreed to be difficult. Some deny the difficulty by ignoring its existence, assuming that these cases form a homogeneous continuum. But even those who share this belief-Garmany (1958) for instanceadmit discrepant results from treatment and, moreover, that there are differences in symptomatology between those who respond, say, to E.C.T., and those who do not.

Imipramine, as many clinical trials-all but a handful, alas, uncontrolled-have shown, is an effective agent in the treatment of depressive illness. However, substantial numbers of patients fail to show any sustained response to the drug.

When a double-blind controlled study of the effects of imipramine upon depressive states was undertaken it was felt that it would be of value to investigate the relationship between the individual symptoms and improvement with the drug and also to establish whether or not those symptoms which are correlated with recovery fall into any recognizable pattern. Such information would clearly have predictive value in assessing the likely response of any particular patient to the drug and would also help to define more precisely its place in the treatment of depressive illness.

The group of patients treated was felt to be peculiarly suitable for an investigation of this kind as they were all out-patients, the more severe varieties of depression being necessarily excluded. They constituted a group, in fact, in which the precise diagnosis was often hard to make with conviction.

\section{Method}

The material consisted of 97 examples of depressive states, all treated with imipramine. Many, but not all, of these patients were included in a double-blind controlled trial of the effects of imipramine reported by Ball and Kiloh (1959) and Kiloh and Ball (1961). The group included 59 cases regarded as suffering from neurotic depression and 38 from endogenous depression, the diagnosis being agreed by the two clinicians concerned in each case. It was fully recognized that in some of the patients the probabilities upon which the diagnosis rested were of a lower order than desirable.

In each case 60 items were assessed, including personal details, personality factors, information about the family history, the clinical features, the diagnosis, details of the treatment and response, certain social features, together with the results of the Wechsler-
Bellevue vocabulary scale, of the Maudsley personality inventory, and the Ponderal index (Parnell, 1958) (see Table I). Where appropriate these items were graded on a four-point scale. Owing to the limitations of the Ferranti Pegasus computer, which was employed to process the data, it was necessary to reduce the number

TABLE I.-Summary of Data Recorded in Cases of Depressive States

(a) "Reactivity of depression" implies a mood which responds quickly to environmental changes: " variability of illness" is present when the symptoms vary greatly in intensity on a day-to-day or week-to-week basis.

(b) Those items marked with an asterisk were rated on a four-point scale.

(c) Items in italics were the variables finally selected for the calculation of weighting coefficients.

$\begin{array}{lc}\text { 1. Age } & \text { Personal Details } \\ \text { 3. Marital status } & \text { 2. Sex } \\ & \text { Family History } \\ \text { 4. Affective psychosis } & \text { 5. Neurosis } \\ \text { 6. Psychopathy } & \text { 7. Other functional psychosis } \\ & \text { Personality Traits } \\ \text { 8. Anxiety } & 9 . \text { Obsessionality } \\ \text { 10. Reactive depression } & \text { 11. Invalidism and immaturity }\end{array}$

11. Invalidism and immaturity

Previous History
13. Number of previous attacks
14. Response to E.C.T. (if given) in
previous attacks

Present Illness

$\begin{array}{ll}\text { 15. Duration } & \text { 16. Mode o onset (insidious or sudden) } \\ \text { 17.* Precipitants } & \text { 18.* Depth of depression }\end{array}$

19. Quality of depression

21.* Self-reproach or guilt 22.* Subjective retardation

23.* Agitation (motor restlessness) 24.* Self-pity

25.* Suicidal ideas 26. Suicidal attempt

27. Weight loss in pounds

29.* Subjective anxiety

31. Irritability

33. * Failure of concentration

35.* Depersonalization

37. * Paranoid features

39. Obsessional features

41. Initial insomnia

43. Early awakening

28. Diurnal variation of depression

30.* Tension

32. * Fatigue

34.* Phobias

36. * Hypochondriasis

38. Hysterical features

40. Variability of illness

42. Restless sleep

44. Coexistent physical disease

45. Number of siblings

47. Social class of patient

51. Migration (and age)

Social Features

46. Number of children

50. Place of birth.

Test Results

52. Ponderal index (Parnell, 1958) 53. Wechsler-Bellevue vocabulary

54. Maudsley personality inventory scale
55. Response
Response to Treatment
57. Time of maximal improvement 58. Duration of administration
56. Time of commencement of improvement 59. Gain of weight
60. Side-effects

of items investigated to 36 (see Table I). Some were discarded because it was felt the information was unreliable-this applied particularly to the details of the family history ; others because preliminary assessments of their relationships to response suggested they were relatively unimportant.

\section{Results}

The results of treatment with imipramine in this group of 97 patients assessed at six months are given in Table II. Those recorded as showing a good result responded to the drug within four weeks and, having done so, remained well continuously until the final

TABLE II.-Results of Treatment of 97 Cases of Depression with Imipramine Assessed at Six Months

\begin{tabular}{|c|c|c|c|c|}
\hline & & & Endogenous Depression & Neurotic Depression \\
\hline $\begin{array}{l}\text { Good result } \\
\text { Poor ", }\end{array}$ & $\cdots$ & 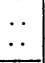 & $\begin{array}{r}32(84 \%) \\
6(16 \%) \\
\end{array}$ & $\begin{array}{l}25(42 \%) \\
34(58 \%)\end{array}$ \\
\hline Total & & $\ldots$ & 38 & 59 \\
\hline
\end{tabular}


assessment was made six months after starting treatment. They were either free from symptoms or, if symptoms persisted, these were mild enough to permit the patient a full range of activities.

A discriminant function analysis (Rao, 1952) was carried out on the data. The object of such an analysis is to find those weighting coefficients which, when applied to the variables (in this case the 36 clinical features), discriminate best between two groups-in other words, those patients who benefited from imipramine and those who did not. It is impracticable to carry out an analysis of this magnitude by hand ; an electronic computer is a practical necessity.

In order that a standard multiple regression computer programme could be used, scores of 1 and 0 were assigned to the two response groups-that is, those patients who benefited from imipramine and those who did not-respectively, so that the correlation coefficients between response and each of the 36 clinical features could be calculated. Use of these correlations gives the same result as the more usual form of calculation, which maximizes the weighted mean distance between the two response groups.

A score of 1 was assigned to each clinical feature when present, and a score of 0 when absent, except that in the case of the following features 0 was assigned to absent or slight and 1 assigned to moderate or severe : intensity of depression, reactivity of depression, agitation, anxiety, tension, fatigue, failure of concentration, and variability of illness. Moreover, age was scored 1 for 40 years and over and 0 for under 40 years ; quality of depression, 1 for different from "normal" depression and 0 if the same; previous attacks, 1 for one or more attacks and 0 for none; onset, 1 for insidious and 0 for sudden; duration, 1 for one year or less and 0 for over 1 year. Correlation coefficients, weighting coefficients, and multiple correlations were calculated by the computer, using these scores.

The multiple correlation between the 36 weighted features and response was 0.74 . The weights and multiple correlation of the 16 features which contributed most of the total multiple correlation of 0.74 were then calculated. The multiple correlation obtained from these 16 features was 0.66 , only 0.08 less than from all 36 clinical features. This difference is not significant. Thus almost as good a discrimination between response groups is obtained from 16 as from 36 features. The 16 features are listed in Table III, together with their correlation coefficients with response, their weighting coefficients, and the number of patients scoring 1 for each feature.

TABLE III

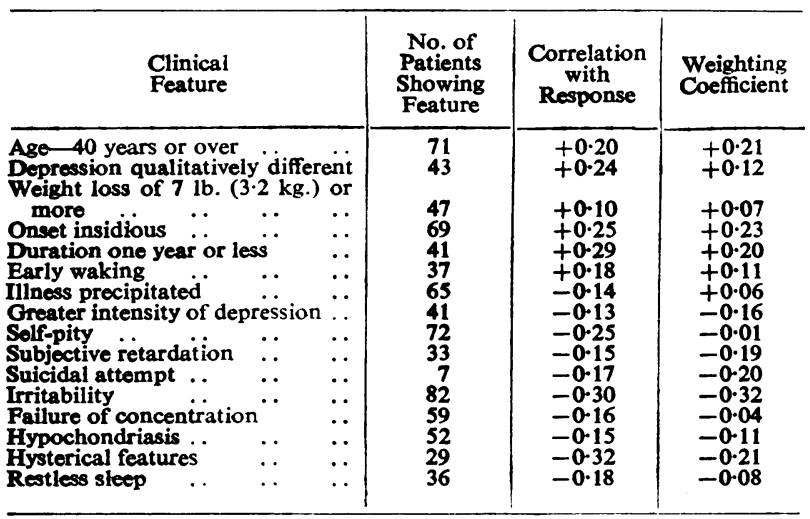

It will be seen from Table III that six features have a positive correlation with response. This means that a score of 1 for any of these six features is suggestive of a good response to imipramine, whereas a score of 0 indicates a poor response. Ten of the features have a negative response correlation, a score of 1 therefore suggesting a poor response and a score of 0 a good response to imipramine.

If two or more features have some underlying factor in common then their individual predictive importance is reduced; thus the weighting coefficients in Table III depend upon the intercorrelations between 16 features as well as upon their correlations with response. This is why the weighting coefficients are dissimilar to the corresponding correlations with response; the presence of "precipitants," for example, has a negative response correlation yet a positive weight. Thus by itself the presence of precipitants suggests a poor response, yet when the 16 features are considered as a whole the presence of precipitants has a small positive weight because the remaining 15 features more than cover the adverse effect of precipitants upon response.

The response correlations are all greater than their standard errors and thus the differences between any one of the positive correlations and each of the negative correlations are all statistically significant. This suggests that the features divide themselves into two more or less distinct groups-those suggesting a good response and those suggesting a poor response to imipramine.

\section{Discussion}

The results indicate that a good response is more likely to occur when imipramine is given to patients with depressive states if the illness comes on insidiously without precipitation by psychogenic factors; when the age of the patient is 40 years or more ; if the depression is qualitatively different from "normal" depression and is associated with early waking; if the duration of the illness is under one year; and if a weight loss of $7 \mathrm{lb}$. $(3.2 \mathrm{~kg}$.) or more is evident. These are some of the features which are commonly accepted as constituents of the clinical picture of endogenous depression. On the other hand, younger patients in whom depression is of sudden onset and is provoked by environmental difficulties; who are irritable, are unable to concentrate, are sorry for themselves, and experience restless sleep with or without initial insomnia ; and who may show hysterical features or hypochondriasis, tend to do badly. These are patients that are sometimes classified as suffering from neurotic, reactive, or psychogenic depression.

A number of clinical features which in view of this dichotomy might have been anticipated to correlate with response, such as morning aggravation of the depression and feelings of guilt and unworthiness, failed to do so significantly. This may be a reflection of the limited range of depressive patients used in this investigation ; relatively few, for instance, were sufficiently depressed to experience anything marked in the way of delusions of guilt or even ideas of self-reproach.

Some of the clinical features showing a correlation with outcome deserve further comment. At first sight it seems somewhat surprising that intensity of depression should be correlated negatively with a good response to treatment, but it is interesting that Hamilton and White (1960), in assessing the outcome of depressive states treated with E.C.T., noted the same phenomenon 
-that the prognosis of the more severely depressed patients is likely to be worse. It is in accord, too, with the widely held clinical impression that the main value of antidepressant drugs is in the milder forms of depression. The negative correlation of subjective retardation with outcome also requires further discussion. Objective psychomotor retardation was present in only a few patients and was included under the heading "subjective retardation," being rated as severe. In the great majority of cases assessed as showing slight or moderate retardation the slowness of thinking or of movement was subjective only. Subjective retardation should not be equated with true psychomotor retardation.

Even if the traditional dichotomy into endogenous and neurotic depression is not accepted-if, as Lewis (1934) and others believe, there is a continuous gradation from one to the other-these findings are still relevant, as they provide a basis for predicting the effects of imipramine in any individual patient. The results can be regarded in another light as providing evidence that endogenous and neurotic depression are separate entities. The 97 cases were rescrutinized and those regarded as falling into each of these two diagnostic categories were subdivided into those in whom the diagnosis could be made confidently and those in whom there was room for doubt.

The diagnosis of endogenous depression was made with confidence when the previous personality of the patient was good without limiting neurotic traits; when the illness came on insidiously without precipitation; when the depth of depression showed little or no variation from day to day, tending to be unaffected by environmental changes, though perhaps showing early morning aggravation; when the patient showed early morning waking perhaps associated with ideas of selfabnegation or of guilt; and when psychomotor retardation or agitation was evident. Neurotic depression was diagnosed when the illness occurred in younger individuals showing obvious neurotic personality traits; when it appeared suddenly in relation to precipitants; when the symptom of depression varied markedly in response to environmental changes and showed a wider fluctuation over periods of days or weeks; when such features as irritability, fatigue, phobias, depersonalization, hypochondriasis, or hysterical components were prominent; and when the sleep disturbance took the form of initial insomnia. Response to treatment was given no consideration in making the decision in these cases.

Among the 38 cases of endogenous depression the diagnosis was accepted as reasonably certain in 15 , and of the 59 cases of neurotic depression there seemed little doubt about the diagnosis in 32. Assessment of the response to treatment in these smaller groups (see Table IV) shows a very marked trend which might have been predicted from the earlier results. Of the 15 patients with endogenous depression, 14 improved and

TABLe IV.-Response of “Definite" Cases of Endogenous and Neurotic Depression to Imipramine, Assessed at Four Weeks and Six Months

\begin{tabular}{|c|c|c|c|c|c|}
\hline & & \multicolumn{2}{|c|}{ Endogenous Depression } & \multicolumn{2}{|c|}{ Neurotic Depression } \\
\hline & & At 4 Weeks & At 6 Months & At 4 Weeks & At 6 Months \\
\hline $\begin{array}{l}\text { Good result } \\
\text { Poor ", }\end{array}$ & $\therefore$ & $\begin{array}{c}14(93 \%) \\
1(7 \%)\end{array}$ & $\begin{array}{c}14(93 \%) \\
1(7 \%)\end{array}$ & $\begin{array}{l}16(50 \%) \\
16(50 \%)\end{array}$ & $\begin{array}{l}11(34 \%) \\
21(66 \%)\end{array}$ \\
\hline Total & .. & 15 & 15 & 32 & 32 \\
\hline
\end{tabular}

At 4 weeks $\chi^{2}=6.54, \mathrm{P}<0.02$; at 6 months $\chi^{2}=11.99, \mathrm{P}<0.01$. remained well after six months, while of the 32 patients with neurotic depression 16 showed a good initial response but only 11 remained well after six months.

After surveying the clinical features which indicate a good prognosis with imipramine treatment it seems reasonable to suggest that this drug is indicated principally in cases showing the features we associate with the diagnosis of endogenous depression; while the response of cases showing the features of neurotic depression is much less satisfactory.

\section{Summary}

A discriminant function analysis was carried out on data obtained from 38 cases regarded as suffering from endogenous depression and 59 suffering from neurotic depression.

The weighting coefficients obtained which discriminated best between those cases responding and those failing to respond to imipramine were for the following items. Age over 40 years, a qualitative difference of the subjective experience of depression from "normal depression," weight loss greater than $7 \mathrm{lb}$. $(3.2 \mathrm{~kg}$.), an insidious onset, a duration of under one year, and early waking were positively correlated with a good outcome. The presence of precipitants, a more intense depression, self-pity, subjective retardation, a history of a suicidal attempt, irritability, failure of concentration, hypochondriasis, hysterical features, and restless sleep were all negatively correlated with a good outcome.

The clinical features suggesting a good response to imipramine are some of those commonly regarded as characteristic of endogenous depression, while those suggesting a poor response are characteristic of neurotic depression.

We are grateful to Professor Martin Roth for his encouragement and to Dr. E. S. Page, Director of the computing laboratory, University of Durham, Miss E. D. Barraclough, computer operator, and Miss S. O. Allison for their help in processing the data.

\section{REFERENCES}

Ball, J. R. B., and Kiloh, L. G. (1959). Brit. med. J., 2, 1052. Garmany, G. (1958). Ibid., 2, 341.

Hamilton, M., and White, J. M. (1960). J. ment. Sci., 106, 1031. Kiloh, L. G., and Ball, J. R. B. (1961). Brit. med. J., 1, 168. Lewis, A. J. (1934). J. ment. Sci., 80, 277.

Parnell, R. W. (1958). Behaviour and Physique. Arnold, London. Rao, C. R. (1952). Advanced Statistical Methods in Biometric Research. Wiley, New York.

Readers who were interested in the article "Getting Them Back to Work" (Brit. med. J., 1961, 2, 1772) describing the Ministry of Labour's Industrial Rehabilitation Unit at Perivale, Middlesex, may like to know that a 16-mm. film, "New Lease of Life," depicting the work of these I.R.U.s, is available for hire from the Central Film Library of the Central Office of Information. This film, which was made for international exhibition to medical, industrial, and other interested audiences, traces the case histories of four people suffering from contrasting types of disability, and highlights their progress during their eight weeks' stay at the unit. It was shot at the unit at Waddon, near Croydon, Surrey, and, apart from the four central characters, no actors were employed. The film has won several awards in British and international competitions. Applications for hire should be made to the Central Film Library, Government Buildings, Bromyard Avenue, Acton, London W.3. The number of the film is UK 1561. It is in three reels, and runs for 24 minutes. The hiring charge is $15 \mathrm{~s}$. 